\title{
Atenção À Primeira Infância na Estratégia de Saúde da Família: a Experiência do Cuidado Humanizado
}

\author{
Tardiani, Fernanda Gasparini; Fukui, Marcela Stábile da Silva; Damian, Patrícia Bombicino \\ Nucleo de Saúde da Família 2 da Faculdade de Medicina de Ribeirão Preto - USP - fer.gasp@yahoo.com.br
}

Introdução: a estratégia de saúde da Família realiza o acompanhamento das pessoas nos diferentes ciclos de vida, por meio de atenção integral e contínua ao individuo e sua família, atuando por meio da prevenção e promoção da saúde dentro do contexto social em que estão alocados. a política nacional de humanização corrobora com essa prática e incentiva a valorização dos sujeitos envolvidos no processo de cuidado, bem como a reflexão nos modos de se produzir saúde, lançando mão de ferramentas que potencializam a construção do vínculo, da corresponsabilização e de um processo de cuidado eficaz. Objetivo: Discutir a atuação da equipe de saúde perante um caso clínico que evidenciou questões que ultrapassavam a barreira do cuidado biológico e refletir sobre a percepção cotidiana de que nem sempre a melhor evidência científica produz melhor resultado e satisfação. Métodos: Trata-se de relato de experiência de cuidado multiprofissional em Núcleo de Saúde da Família (NSF). Foram realizadas análises do prontuário familiar e individual e das discussões em reunião de família. a mãe de 31 anos teve parto cesárea; filha recém-nascida (RN) a termo, no nascimento pesava 3220g, estatura de 48,5cm, Apgar 10/10. aos 21 dias de vida a RN mantinha peso $8 \%$ abaixo do de nascimento e não possuía direito ao convênio médico materno. Resultados: a mãe busca o NSF após orientação da agente comunitária de saúde, inicialmente com resistência ao serviço por desconhecer sua atuação e, atrelado a isso, demonstrava grande preocupação com o ganho de peso inadequado da filha e dificuldade em amamentar. Mãe e filha foram acolhidas, realizou-se orientação sobre aleitamento materno, enfatizando sua importância e técnica adequada. Sem sucesso, foi utilizada medicação na tentativa de aumentar a produção de leite e diminuir ansiedade materna bem como a irritabilidade da criança. a mãe comparecia semanalmente no NSF para avaliação do peso da RN, permitindo estreitamento do vínculo. Diante da estafa materna, foi introduzido fórmula láctea artificial, no copinho e/ou sob técnica de relactação, após oferecer seio materno. Mantendo o estresse da mãe, o prejuízo evidente de sua autoestima, e os entraves que se estava criando na relação mãe-filho, orientou-se aumentar a quantidade de fórmula já na mamadeira. Dessa forma, obteve-se crescimento e desenvolvimento adequado de uma criança que estava em risco de subnutrição, com qualidade de vida e estreitamento dos laços materno-infantil e da família com o NSF. Conclusão: o processo de cuidar está atrelado a compreender o contexto dos sujeitos envolvidos, lidando muitas vezes com ambiguidades e incertezas. a humanização deste processo permite que se ultrapasse a barreira da teoria e evidencia que a satisfação com o cuidado e a aquisição de saúde no seu significado mais amplo é proporcional à interligação que o profissional consegue exercer entre ciência e arte, ou seja, entre conhecimento técnico e relação profissional-paciente.

Tardiani, Fernanda Gasparini; Fukui, Marcela Stábile da Silva; Damian, Patrícia Bombicino. Atenção À Primeira Infância na Estratégia de Saúde da Família: a Experiência do Cuidado Humanizado. In: Anais do Congresso Internacional de Humanidades \& Humanização em Saúde [= Blucher Medical Proceedings, num.2, vol.1]. São Paulo: Editora Blucher, 2014. ISSN 2357-7282

DOI 10.5151/medpro-cihhs-10614 